\title{
Non-nutritional determinants of satisfactory growth among infants and pre-school children in low income communities in Ja-Ela Medical Officer of Health area, Sri Lanka
}

\author{
Champa K Gunathunga ${ }^{1}$, Wasantha Gunathunga ${ }^{2 *}$, Shyaminda Basnayake ${ }^{1}$, Punya Arunoda ${ }^{2}$ \\ ${ }^{1}$ Ministry of Health, Sri Lanka; ${ }^{2}$ Department of Community Medicine, University of Colombo, Sri Lanka \\ *Correspondence: wasantg@commed.cmb.ac.lk
}

DOI: https://doi.org/10.4038/jccpsl.v23i2.8099

Received on: 9 March 2017

Accepted on: 15 June 2017

\begin{abstract}
Background: In Sri Lanka, poor growth of infants and pre-school children is a persistent concern with $14 \%$ of them having low weight for height. It has been observed that some infants grow well and develop successfully even in low income set-ups despite many unfavourable circumstances, a phenomenon that has not been studied adequately.
\end{abstract}

Objective: To describe the non-nutritional determinants of positive growth among infants and pre-school children in low income communities in Sri Lanka.

Methods: An unmatched case control study including a qualitative arm was carried out. Cases were 'well grown' and controls were 'poorly grown' infants and pre-school children in Ja-Ela Medical Officer of Health area, who were recruited from the child welfare clinic and at home. Growth was determined by weight for age using standard procedure. An interviewer-administered questionnaire obtained data from their mothers/caretakers on the potential determinants of growth. Ten of the cases were randomly selected for the qualitative study and their mothers underwent in-depth interviews.

Results: A total of 51 cases and 67 controls were recruited for the study. Their average family income was Rs. 17,700 ( $S D=4200)$. Cases and controls did not differ significantly by the mode of delivery, type of pregnancy, order of pregnancy and whether pregnancy was planned or not. The only non-nutritional determinants of positive growth were: whether the child is easy to be fed (OR=3.58; 95\% CI: 1.66, 7.72) and corporative with the mother (OR=3.77; 95\% CI: 1.05, 13.54). The qualitative study further identified readiness to eat and preference for a wide variety of food as non-nutritional determinants of positive growth, which seemed to be intrinsic characteristics of a child rather than shared features among the siblings in a family.

Conclusions: Intrinsic characteristics of a child such as readiness to eat, cooperating with the mother and preferring a variety of food partly determine good growth. Dynamics of these characteristics need further study.

Key words: non-nutritional determinants, growth, infants and pre-school children, low socio-economic 


\section{Introduction}

Sri Lanka is a low- and middle-income country with a per capita income of USD 3924 (1). Currently, 14\% of the children have low weight for height (2). Numerous interventions have gone into rectifying this situation with limited results (3-5).

Poor growth of infants and pre-school children is a persistent concern in Sri Lanka. To address this issue, nutritional determinants of growth have been studied widely. Many studies have looked at risk factors for growth faltering (6) and poor compliance with healthy feeding practices in some areas of Sri Lanka (7-8). It has been observed that even in high socio-economic communities with satisfactory nutritional supply, there is a considerable proportion of infants and pre-school children who have sub-optimal growth (9). It has also been observed that some grow well and develop successfully even in low income set ups despite many unfavourable circumstances (10-11), pointing to the assumption that possibly non-nutritional determinants do operate on the growth of children. However, not much attention has been paid as to why and how only some would show above average growth despite being subject to almost the same risk factors prevailing in low socioeconomic environments. Identifying the underlying determinants of good growth in such communities would point to possible nutritional interventions. This approach is particularly useful for a medical officer of health $(\mathrm{MOH})$ as he is expected to take pragmatic action to prevent growth faltering in low income families in his/ her area.

The objectives of this study were to determine the non-nutritional determinants of growth among infants and pre-school children in low-income communities in the district of Gampaha and to explore the possible reasons for growing well against all odds in such communities. The results will shed light on some unseen dynamics of growth that could be applied to uplift the growth of infants and pre-school children living in similar settings.

\section{Methods}

An unmatched case control study was carried out among infants (6 months-one year of age) and preschool children (3-5 years of age) whose parents were of low socio-economic status and living in Ja-Ela $\mathrm{MOH}$ area. Determination of their low socio-economic status was based on a composite index developed using the total family income, occupation of father and education of both parents. Children who were suffering from congenital disorders and chronic diseases were excluded from the study. Cases were 'well grown' infants and pre-school children defined as having a weight between -1 standard deviation (SD) and + 2 SD of the median. Controls were 'poorly grown' infants and pre-school children defined as having a weight below -1 SD of the median. Growth was determined by measuring the weight of each participant and plotting it against his/her age in the growth chart of child health development record. Cases and controls were 57 in each group calculated to detect an odds ratio of 3 , presence of non-nutritional determinants in controls of $25 \%$, $\alpha$ error of 0.05 and $\beta$ error of 0.2 (12). The required number of cases and controls fulfilling the eligibility criteria was obtained from lists of infants and pre-school children maintained by the area public health midwife (PHM). Since almost 100\% of babies born are registered with the PHM, all infants in Ja-Ela $\mathrm{MOH}$ had an equal probability of being included in the study.

Mothers/caretakers of the cases and controls were administered a questionnaire by the co-investigators at the child welfare clinic. Those who did not visit the clinics were visited at home to collect data. The questionnaire had five parts. Part one consisted of personal information about the mother and child. Other parts contained non-nutritional variables that were likely to be related to the growth of child, such as the number of pregnancies and living children, pregnancy details (type -singleton or multiple, mode of delivery and whether planned or not), employment status of mother, mother's opinion about how easy to feed the child, whether child is cooperating with the mother and preference of the child for variety of food. To complement this data, a qualitative study was also carried out among ten randomly selected cases to explore the factors that possibly led to their satisfactory growth, which were difficult to be captured in the case control study. The number of cases was determined by the independent variables of key importance and the availability of cases. Mothers/ caretakers of the cases were interviewed at their home by the principal investigator and a trained person. The interviews were open-ended and unstructured. The theoretical framework used was that non-nutritional determinants operate in the growth pattern of infants and pre-school children. An interview guide containing the areas on which qualitative information to be obtained was used. Documentation was done immediately after the interviews. 
Non-nutritional determinants of growth were assessed using odds ratio with 95\% confidence intervals (CI). In the qualitative study, initial interviews identified hypotheses on an on-going analysis. A number of such hypotheses in relation to the factors leading to good growth was developed using grounded theory (13). In subsequent interviews, these hypotheses were either accepted or rejected.

Ethics approval was obtained from the Ethics Review Committee of the Faculty of Medicine, University of Colombo.

\section{Results}

A total of 118 infants and pre-school children who were of low socio-economic status in Ja-Ela $\mathrm{MOH}$ area were recruited for the study. Their average family income was Rs.17,700 ( $\mathrm{SD}=4,200)$ while $90.7 \%$ $(n=107)$ of their mothers were unemployed. At least one family member had been addicted to alcohol or smoking in 19 (16.1\%) families (Table 1).

\section{Table 1. Socio-economic characteristics of the parents of cases and controls $(\mathrm{N}=118)$}

\begin{tabular}{lr}
\hline Socio-economic characteristic & No. (\%) \\
\hline Employment status of the mother & \\
Employed & $11(9.3 \%)$ \\
Not employed & $107(90.7 \%)$ \\
\hline Number of siblings & \\
None & $26(22.0 \%)$ \\
One & $48(40.7 \%)$ \\
Two & $36(30.5 \%)$ \\
Three & $7(5.9 \%)$ \\
Four & $1(0.9 \%)$ \\
\hline Family members addicted to & \\
smoking or alcohol & $19(16.1 \%)$ \\
Yes & $99(83.9 \%)$ \\
No & \\
\hline
\end{tabular}

Of them, $43.2 \%(\mathrm{n}=51)$ showed satisfactory growth (cases) while $56.8 \%(n=67)$ showed unsatisfactory growth (controls) (Table 2). Of the cases, 50.9\% $(\mathrm{n}=26)$ were males and $49.0 \%(n=25)$ were females.

There was no statistically significant association between good growth and mode of delivery ( $\mathrm{OR}=0.56$; $95 \% \mathrm{CI}=0.24,1.14)$, type of pregnancy (OR $=1.14 ; 95 \%$ $\mathrm{CI}=0.19,7.14)$, order of pregnancy (OR=1.46; 95\% $\mathrm{CI}=0.61,3.5)$ and pregnancy being planned or not
Table 2. Weight for age of cases and controls at the time of the interview $(\mathrm{N}=118)$

\begin{tabular}{lrr}
\hline Weight at the time of interview & No. & $\%$ \\
\hline Controls & & \\
Below -2 SD & 34 & $28.8 \%$ \\
Between -2 SD and -1 SD & 33 & $28.0 \%$ \\
\hline Cases & & \\
Between -1 SD and Median & 21 & $17.8 \%$ \\
Between Median and +1 SD & 20 & $16.9 \%$ \\
Between +1 SD and +2 SD & 10 & $8.4 \%$ \\
\hline
\end{tabular}

$(\mathrm{OR}=1.19 ; 95 \% \mathrm{CI}=0.57,2.51)$. The child is easy to be fed $(\mathrm{OR}=3.58$; 95\% $\mathrm{CI}=1.66,7.72)$ and whether the child is corporative with mother or not (OR=3.77; 95\% $\mathrm{CI}=1.05,13.54$ ), both as perceived by mother showed statistically significant associations with the child's good growth (Table 3).

The qualitative interviews uncovered several hypotheses on reasons that led to good growth among cases.

One hypothesis was that 'the children who show good growth have an inborn appetite to eat'. This inborn appetite for eating was apparent among all cases whose mothers were interviewed. It gave the mother more opportunity and willingness to feed the child and mothers seemed to enjoy feeding the child.

"My child is asking for food whenever he sees someone eating. His weight is good and I have no difficulty in feeding him" was the description of one mother.

"My little daughter reminds me to feed her. Sometimes she serves food herself" was the expression of another mother. All mothers gave similar descriptions about the appetite of their children.

In many low socio-economic settings where food availability is limited, a bigger share of whatever the food that is available is allocated for infants and children than for adults (9). Hence, with such readiness to eat, it is possible that such children show better growth than peers with an average appetite.

Another hypothesis generated was that 'the child who is willing to eat a wide variety of available food shows good growth'. This was the case in nine children other than one infant who was selective of food offered. 
Table 3. Association of different exposures to the status of growth in cases and controls

\begin{tabular}{|c|c|c|c|c|c|}
\hline Exposure & $\begin{array}{l}\text { Cases } \\
(n=51)\end{array}$ & $\begin{array}{l}\text { Control } \\
\text { s }(n=67)\end{array}$ & Total & OR & $95 \% \mathrm{CI}$ \\
\hline Normal delivery & 30 & 49 & 79 & 0.56 & $0.24-1.14$ \\
\hline Other (Ref) & 21 & 18 & 39 & 1.00 & \\
\hline Singleton baby & 49 & 64 & 113 & 1.14 & $0.19-7.14$ \\
\hline Twins (Ref) & 2 & 3 & 5 & 1.00 & \\
\hline First pregnancy & 18 & 18 & 36 & 1.46 & $0.61-3.50$ \\
\hline Second and above (Ref) & 33 & 49 & 82 & 1.00 & \\
\hline Planned pregnancy & 22 & 26 & 48 & 1.19 & $0.57-2.51$ \\
\hline Unplanned pregnancy (Ref) & 29 & 41 & 70 & 1.00 & \\
\hline Child can be easily fed & 34 & 24 & 58 & 3.58 & $1.66-7.72$ \\
\hline Cannot be easily fed (Ref) & 17 & 43 & 60 & 1.00 & \\
\hline Child is corporative & 43 & 46 & 89 & 3.77 & $1.05-13.54$ \\
\hline Not corporative (Ref) & 8 & 21 & 29 & 1.00 & \\
\hline
\end{tabular}

Ref = reference category for calculating the odds ratio (OR)

"This child eats whatever I feed him with. So, it is very easy for me to give him a wide variety of food” said one mother. Many others had similar expressions about the variety that the children preferred.

This is in agreement with the already existing knowledge that offering a wide variety of food improves growth.

The last hypothesis was that 'readiness to eat is an individual characteristic rather than a shared feature among siblings in a family'. This was evident by the fact that readiness to eat seeing only among some siblings in the family and not so always in every family.

“This child can be fed at any time unlike my other children” said many mothers.

This inquiry points to the fact that readiness to eat and subsequent good growth is a factor that is partly intrinsic in the child.

\section{Discussion}

Poor growth of infants and preschool children has been a public health issue in developing countries including Sri Lanka (2) despite many remedial measures (5). Sub-optimal growth despite an adequate supply of food while sharing the same circumstances of children with good growth points to the occurrence of nonnutritional determinants that retard the growth.

Case control approach provides an analytical design that can quantitatively determine the factors for good growth among infants and pre-school children of low socio-economic status. On the other hand, qualitative approach provides more depth into understanding the factors for good growth in them. Of the non-nutritional variables studied, pregnancy related facts which were also related to their income indirectly, did not seem to play a significant role in positive growth. In contrast, the ease of feeding and being corporative with the mother were significantly associated with good growth. This evidence was further supported by the qualitative study that identified similar non-nutritional factors such as having a good appetite and readiness to eat, leading to an increased consumption of a wide variety of food that are available for a low income family, and thereby to positive growth. Further, it identified such factors to be mostly intrinsic characteristics of the child, which are independent of the environment they grow up in and not always shared with other siblings. These characteristics however may harness other environmental factors such as mothers' enjoyment and contentment in feeding, which would lead to a positive effect on growth. They are also likely to have an effect on procuring a variety of food items by the other household members too. 
There is evidence to suggest genetic determination of food preferences (14-15). However, the present study indicates that genetic or environmental aetiology alone may not explain the development of natural appetite to eat, readiness to eat and eating a variety in a child. A wealth of non-conventional research, particularly in Asia points to transmigrating components of an individual that may determine their behaviour in present life (16-17). It is worth exploring whether such a relationship can contribute to the aetiology in order to shed new light on this important growth related behaviour of infants and children.

\section{Conclusions and recommendations}

The satisfactory growth of infants and pre-school children of low socio-economic status was associated with child's intrinsic behavioural characteristics such as the ease of feeding the child and the cooperation of child with mother, thus signifying the importance of non-nutritional determinants. Dynamics of these inner characteristics: how these are transmitted congenitally, genetically or otherwise need further study.

\section{Public health implications}

Unsatisfactory growth despite an adequate supply of food points to the occurrence of nonnutritional determinants of growth. It is essential to identify and address these non-nutritional determinants to improve the growth indicators of infants and pre-school children. The present study attempts to identify some of these determinants that will help to set a new trend of thinking allowing important public health decisions to be taken on the determinants of child growth.

\section{Author declarations}

Competing interests: The authors declare that they do not have competing interests.

Ethics approval and consent to participate: Ethics approval was obtained from the Ethics Review Committee of the Faculty of Medicine, University of Colombo (EC-12-178 in December 2012). Administrative clearance was obtained from the Regional Director of Health Services, Gampaha and the Medical Officer of Health, Ja-Ela. Informed written consent was obtained from all the participants.
Funding: none.

Acknowledgement: We would like to acknowledge the support given by the staff of Ja-Ela MOH area and the mothers who participated in the study.

Author contributions: CKG is the principle investigator. CKG and MWG contributed in designing of the study, analysis and interpretation of data, and finalizing the article. CKG, PA and SB contributed in data collection, data entry and writing the draft article.

\section{References}

1. The World Bank. Overview Sri Lanka. Available from:http://www.worldbank.org/en/country/ srilanka/overview.

2. DCS. Demographic and Health Survey 2006-07. Colombo: Department of Census and Statistics, 2009.

3. Ministry of Health \& UNICEF Sri Lanka. Improving the practice of complementary feeding: experience from a community based programme in Hambantota district. Colombo: Ministry of Health, 2015.

4. Family Health Bureau. National Strategy for Infant and Young Child Feeding 2015-2020. Colombo: Ministry of Health \& Indigenous Medicine, 2015.

5. MRI, UNICEF \& WFP. Assessment of nutritional status and food security levels among resettled families. Colombo: Medical Research Institute, UNICEF \& World Food Program, 2010.

6. Rajapaksa L, Arambepola C, Gunawardena N. Nutritional status in Sri Lanka, determinants and interventions: a desk review 2006-2011. Colombo: UNICEF, 2011.

Available from: http://files.unicef.org/srilanka/2012_ SL_Nutri_Desk_review.pdf.

7. Athauda GATK \& Fernando DN. Morbidity patterns among pre-school children of migrant mothers in Sri Lanka. Journal of the College of Community Physicians of Sri Lanka 2002; 7: 26-31.

8. Jayatilleka A, Fernando DN. A community based study on breast feeding practices in Gampaha district. Journal of the College of Community Physicians of Sri Lanka 2002; 7: 32-36.

9. Al Frayh AS, Bamgboye EA. The growth pattern of Saudi Arabian pre-school children in Riyadh compared to NCHS/CDC reference population. Journal of the Royal Society of Health 1993; 113(5): 234-9.

Available from: http://www.ncbi.nlm.nih.gov/pubmed/ 8230073. 
10. Runyan DK, Hunter WM, Socolar RR, Amaya-Jackson L, English D, Landsverk J, Dubowitz H, Browne DH, Bangdiwala SI, Mathew RM. Children who prosper in unfavourable environments: the relationship to social capital. Pediatrics 1998; 101(1):12-8.

Available from: https://www.ncbi.nlm.nih.gov/pubmed/ 9417144.

11. Kalil A. Family resilience and good child outcomes: areview of the literature.Centre for Social Research and Evaluation, Ministry of Social Development, Te Manat Whakahiato Ora, 2003.

Available from: https://www.google.lk/search?q= good + child+growth+in+unfavourable+circumstance \&rlz=1C1NHXL_enLK683LK684\&oq=good+child + growth+in+unfavourable+circumstance $\&$ aqs $=$ chrome..69i57.18367j0j7\&sourceid= chrome\&ie=UTF-8.

12. Schlesselman JJ. Case-control studies: design, conduct, analysis. Oxford University Press, 1982.
13. Annells, M. Grounded theory method: philosophical perspectives, paradigm of inquiry and postmodernism. Qualitative Health Research 1996; 6(3); 379-393.

14. Marsh DR, Schroeder DG, Dearden KA, Sternin J, Sternin M. The power of positive deviance. British Medical Journal 2004; 329(7475): 1177.

15. Scaglioni S, Arrizza C, Vecchi F, Tedeschi S. Determinants of children's eating behaviour. The American Journal of Clinical Nutrition 2011; 94(6): 2006S-2011S.

Available from: http://ajcn.nutrition.org/content/94/ 6_Suppl/2006S.full

16. Garret F. Religion, medicine and human embryo in Tibet. London and New York: Routledge, Tailor and Francis Group, 2008:136-140.

17. Maha-nidana Sutta: The great causes discourse translated from the Pali by Thanissaro Bhikkhu,1997. Available from:http://www. accesstoinsight.org/tipitaka/dn/ dn.15.0.than.html 